\title{
Tratamentos ofertados em Comunidades Terapêuticas: Desvelando práticas na Amazônia Ocidental
}

Leila Gracieli da Silva. Faculdade de Ciências Biomédicas de Cacoal.

Luís Fernando Tófoli. Universidade Estadual de Campinas.

Paulo Renato Vitória Calheiros. Universidade Federal de Rondônia.

\section{Resumo}

Este artigo apresenta as atividades empregadas por Comunidades Terapêuticas (CTs) como tratamento para transtornos relacionados ao uso de substâncias psicoativas na capital de Rondônia, Porto Velho. Para coleta de dados utilizou-se um questionário estruturado, elaborado com base em pesquisas na literatura especializada e nas legislações norteadoras, aplicado em 18 instituições CTs. Os resultados evidenciaram predomínio de instituições filantrópicas em detrimento de serviços públicos; escassez de profissionais especializados; taxas elevadas de abandono do tratamento; maior oferta de atendimento para homens; terapêuticas centradas em práticas religiosas e na abstinência como meta terapêutica; ausência de critérios de ingresso, elegibilidade, alta e pós-alta; além da desarticulação com a rede de saúde mental. Por fim, estes dispositivos carecem de intervenções coordenadas que englobem desde o mapeamento e cadastro das CTs até capacitações, planejamento, avaliação e monitoramento - priorizando a eficácia dos protocolos clínicos e a oferta de serviços humanizados - tal qual devem ser quaisquer serviços de saúde.

Palavras-chave: transtornos relacionados ao uso de substâncias; comunidades terapêuticas; tratamentos.

\begin{abstract}
Treatment for substance abuse in Therapeutic Communities: Understanding practices in Western Amazon. This paper presents the activities employed by Therapeutic Communities (CT in Portuguese) as treatment for disorders related to psychoactive substance abuse in Porto Velho, Rôndonia. A structured questionnaire was used for data collection, based on research of specialized literature and Brazilian law. Overall, 18 institutions, represented by their leaders, participated in the survey. The results showed a predominance of philanthropic institutions in detriment of public services; shortage of specialized professionals; high dropout rates; greater offer of care for men; religious activities centered on prayer and abstinence as a therapeutic goal; lack of admission, eligibility, discharge, and post-discharge criteria; as well as disarticulation with official mental-health network. Finally, these institutions lack coordinated interventions, ranging from mapping and CT registration to training, planning, evaluation and monitoring. They do not prioritize the effectiveness of clinical protocols or the provision of humanized services, as should be done by any health service.
\end{abstract}

Keywords: substance-related disorders; therapeutic communities; treatments.

\section{Resumen}

Tratamientos ofrecidos en comunidades terapéuticas: Prácticas desvelado en el Amazonas occidental Este artículo presenta las actividades empleadas por las comunidades terapéuticas (CTs) como tratamiento para los trastornos relacionados con el uso de sustancias psicoactivas en la capital de Rondonia, Porto Velho. Para la recolección de datos, se utilizó un cuestionario estructurado, elaborado sobre la base de investigaciones en la literatura especializada y en las legislaciones orientadoras, aplicadas en 18 instituciones. Los resultados mostraron un predominio de las instituciones filantrópicas en detrimento de los servicios públicos; Escasez de profesionales especializados; Altas tasas de abandono del tratamiento; Mayor provisión de atención a los hombres; Terapias centradas en las prácticas religiosas y la abstinencia como objetivo terapéutico; Ausencia de admisión, elegibilidad, altos y post-aprobación de los criterios; Además de la desarticulación con la red de salud mental. Por último, estos dispositivos carecen de intervenciones coordinadas que abarcan el mapeo y registro de CTs a capacitaciones, planificación, evaluación y seguimientopriorizando la eficacia de los protocolos clínicos y la provisión de servicios humanizados-tales Qué servicios de salud deben ser. Palabras clave: trastornos relacionados con el uso de sustancias; comunidades terapéuticas; tratamientos. 
Longe de ser um fenômeno atual (Bolonheis-Ramos \& Boarini, 2015), o uso de substâncias psicoativas é praticado com diferentes finalidades desde os primórdios da civilização (Vasconcelos, Paiva, \& Dalla Vecchia, 2018). Na contemporaneidade, os transtornos decorrentes do uso de substâncias psicoativas são considerados um problema de saúde mental, que afeta aspectos físicos, psicológicos, comportamentais e sociais (American Psychiatry Association, 2013). Em virtude disso, o tratamento adequado implica em intervenções eficazes na redução e/ou interrupção do consumo, que visem a melhora na saúde do indivíduo, a prevenção de danos, a reinserção social e o desenvolvimento de estratégias para o enfrentamento do cotidiano pós-tratamento (M. Ribeiro, 2010).

No Brasil, os debates acerca dos tratamentos para uso problemático de substâncias psicoativas reivindicam a adequação das intervenções à demanda e a precariedade das atuais terapêuticas ofertadas (L. G. Silva \& Calheiros, 2017). No campo das Políticas Públicas sobre drogas, as alternativas de tratamento percorrem um caminho de progressos e retrocessos, oscilando entre políticas e práticas contraditórias de cuidado que persistem na internação e isolamento dos usuários de álcool e outras drogas, com mais ações na área da segurança do que na saúde (Bolonheis-Ramos \& Boarini, 2015).

Estas lacunas na assistência à saúde impulsionaram a participação de diversos dispositivos na acolhida a usuários de álcool e outras drogas, principalmente entidades religiosas, o que fomentou o surgimento das comunidades terapêuticas (CTs) (Bolonheis-Ramos \& Boarini, 2015). A definição de CTs comumente empregada é a de que são locais que ofertam "cuidados contínuos de saúde, de caráter residencial transitório, por até nove meses, para adultos, com necessidades clínicas decorrentes do uso de crack, álcool e outras drogas" (Ministério da Saúde, 2011, p. 6).

Recentemente, o Ministério da Saúde divulgou a Nota Técnica 11/2019 vinculando oficialmente as CTs aos demais dispositivos de saúde mental na tentativa de fortalecer a Rede de Assistência Psicossocial RAPS. Segundo a referida Nota, o Brasil precisa de diversos tipos de serviços para suprir a demanda vigente e ofertar tratamentos válidos e aplicáveis aos usuários.

Acerca dos tratamentos ofertados em CTs brasileiras, F. M. L Ribeiro e Minayo (2015) analisaram o papel de 14 comunidades na recuperação e reabilitação de usuários de psicoativos do complexo de favelas de Manguinhos, no Rio de Janeiro. Os resultados evidenciaram dois pontos centrais na elaboração dos planos terapêuticos ofertados: o uso problemático de substâncias visto como pecado/fraqueza, falta de Deus ou possessão demoníaca e a abstinência como o único caminho para a recuperação. Observaram ainda o emprego de orações, práticas de evangelização e conversão religiosa elencadas como principais intervenções terapêuticas.

Corroborando, a pesquisa de Silva e Garcia (2004), realizada em CTs do Espírito Santo, apontou que a maioria das instituições é pautada em preceitos religiosos e psicossociais e que as atividades visam manter o paciente constantemente ocupado "nas áreas espiritual, ocupacional, recreativa e física" (p.243). A equipe de profissionais atuantes era composta por voluntários, conselheiros espirituais e monitores (em geral ex-internos), sendo rara a atuação de profissionais com formação específica.

Destoando da realidade brasileira, dados do Observatório Europeu de drogas e substâncias de abuso (Vanderplasschen, Vandevelde, \& Broekaert, 2014) apontam que as CTs europeias não são consideradas como serviços de saúde, nem como modalidades de tratamento e tampouco como instituições de cunho religioso. Acrescenta-se que na Europa há avaliação constante dos programas por peritos com o intuito de assegurar a qualidade dos serviços ofertados, além de o governo possuir dados reais das CTs atuantes, algo que não acontece no Brasil.

Na Espanha (Arnau, 2006), dentre os objetivos terapêuticos norteadores dos tratamentos ofertados em CTs destacam-se a singularidade no estabelecimento das metas de intervenção; o foco em problemas relacionados à saúde (patologias orgânicas e psiquiátricas comórbidas); a atenção especial à fase de desintoxicação e abstinência (intervenção medicamentosa quando necessário, exames de controle, prevenção à recaídas); o estabelecimento de rotinas (alimentação, sono, estilo de vida); aspectos psicológicos (autoestima, consciência do problema, motivação para mudança, habilidades sociais, demonstração de afeto e manejo das emoções, reestruturação cognitiva); e fatores sociais (reconstrução das relações familiares, intervenções com a família do interno, problemas com a justiça, auxílio na reinserção ao mercado de trabalho e comunidade).

Problematiza-se o quanto os tratamentos ofertados em CTs caminham na "mão ou na contramão" da reforma psiquiátrica brasileira (M. A. R. Silva, 2013) e quais são seus reais objetivos: proselitismo ou 
tratamento de saúde. Ainda que a existência das CTs seja do conhecimento da sociedade brasileira, das entidades governamentais e da academia científica, ainda são escassas as informações acerca de como ocorrem as intervenções elencadas como tratamento nestes locais (L. G. Silva \& Calheiros, 2017) - fato que impossibilita atestar a validade e aplicabilidade dos mesmos.

Na prática, cada CT emprega diversas atividades na condição de tratamento (J. M. Ribeiro, Moreira, Bastos, Inglez-Dias, \& Fernandes, 2016), dificultando a articulação com o Sistema Único de Saúde (SUS) e com a RAPS. Esta pesquisa teve como objetivo norteador identificar as práticas ofertadas como tratamento para o uso problemático de substâncias psicoativas nas comunidades terapêuticas da capital de Rondônia, Porto Velho.

\section{Metodologia}

Este trabalho é fruto da dissertação de mestrado intitulada "Tratamentos ofertados em comunidades terapêuticas na capital de Rondônia: desvelando práticas", aprovado pelo Comitê de Ética em Pesquisa com seres humanos da Universidade Federal de Rondônia (UNIR) pelo Parecer $N^{\circ}$ 1.128.527. Trata-se de um estudo com caráter descritivo, abordagem quantitativa e recorte transversal.

A identificação das instituições ocorreu a partir do mapeamento realizado em 2012 pela Superintendência de Estado de Políticas sobre Drogas (SEPAZ-RO), o qual identificou 12 CTs. Todavia, no intuito de englobar todas as CTs existentes, incluindo as criadas após o referido mapeamento, aplicou-se o método "bola de neve", solicitando aos dirigentes/participantes a indicação de outras instituições. Seis instituições foram incluídas, perfazendo o total de 18 Comunidades Terapêuticas, todas localizadas em Porto Velho/RO, as quais compõem a amostra deste estudo. Os dados foram coletados entre agosto de 2015 e março de 2016.

Foram consideradas as seguintes variáveis: caracterização do perfil das CTs existentes e descrição dos aspectos institucionais; composição da equipe técnica; participação em cursos de capacitação e por quais entidades; clientela atendida e substâncias de abuso; modalidades de tratamento e práticas empregadas; a identificação do que é ofertado como laborterapia; critérios de ingresso, elegibilidade, alta, índice de desistência do tratamento e se há, e como ocorre o contato pós-alta.
Para a coleta dos dados, foi utilizado um questionário estruturado, originalmente desenvolvido por Spohr, Leitão e Schneider (2006), cuja finalidade é identificar as ferramentas utilizadas no atendimento e tratamento de usuário de substâncias psicoativas. Adaptou-se o instrumento com a retirada das questões qualitativas e o acréscimo de questões relacionadas ao emprego de práticas religiosas e atividades de laborterapia, elencando a descrição (tipo) e a frequência com que ocorrem, totalizando 35 questões.

A aplicação do instrumento foi realizada no formato de entrevista estruturada por psicólogos devidamente treinados. As entrevistas tiveram duração aproximada de 60 minutos e ocorreram nas próprias CTs. A coleta dos dados ocorreu entre os meses de junho e agosto de 2015, respeitando a dinâmica de funcionamento e disponibilidade dos participantes. Todos os participantes eram maiores de 18 anos e consentiram em participar de forma livre e esclarecida, representando as instituições. Tendo em vista os objetivos norteadores do estudo, a análise das características investigadas foi feita por meio da descrição dos valores absolutos e suas respectivas porcentagens (Morais, 2007).

\section{Resultados}

Responderam à pesquisa todas as CTs credenciadas na SEPAZ (12) mais aquelas identificadas no método "bola de neve" (seis), totalizando 18 instituições localizadas em Porto Velho/RO que se autodenominaram Comunidade Terapêutica. Todas estas instituições são de caráter filantrópico, sendo que apenas uma CT afirmou realizar planejamento financeiro e três $(16,6 \%)$ relataram receber verbas públicas (para financiamento de leitos). As demais são mantidas por doações de instituições religiosas, mas também recebem auxílio de familiares dos internos e empresários locais.

As internações ocorrem de forma voluntária e nenhuma instituição relatou aceitar a internação compulsória. No entanto, ao consentir em internar-se, o interno deve seguir as regras da CT. O atendimento é gratuito em todas as instituições, sem custos obrigatórios diretos ao indivíduo ou a sua família. O tempo de internação em três $(16,6 \%)$ instituições dura 6 meses, em uma (5,5\%) 12 meses e em 14 (77,7\%) CTs a internação dura 9 meses. Em todas as CTs a equipe de trabaIho engloba egressos - que assumem a função de monitores. 
A amostra foi dividida em perfis (Tabela 1) e as CTs foram distribuídas em grupos, classificados como: regular, parcialmente regular e irregular. O grupo regular engloba as instituições consonantes com as normas da Agência Nacional de Vigilância Sanitária (ANVISA, 2011) e a Rede de
Atenção Psicossocial; o grupo parcialmente regular é composto pelas CTs em conformidade apenas com as normas da ANVISA; foram elencadas como irregular as instituições que não apresentaram nenhum critério normativo, mas que se auto intitularam comunidades terapêuticas.

Tabela 1. Perfil das Comunidades Terapêuticas de Porto Velho/Ro

\begin{tabular}{|c|c|c|c|c|c|}
\hline Perfil & $\begin{array}{l}\text { Tempo de existência } \\
\text { da CT }\end{array}$ & $\begin{array}{l}\text { Capacidade de } \\
\text { atendimento }\end{array}$ & $\begin{array}{l}\text { Total da } \\
\text { equipe }\end{array}$ & Especialidade dos profissionais & Índice de desistência \\
\hline $\begin{array}{l}\text { Regular } \\
3 \text { CTs }\end{array}$ & $\geq 240$ meses & $\begin{array}{l}\text { Entre } 10 \text { e no máximo } \\
35 \text { pessoas }\end{array}$ & $10-15$ & $\begin{array}{c}\text { Psicólogos; Assistentes Sociais; téc/ } \\
\text { aux enfermagem; educador físico; } \\
\text { nutricionista }\end{array}$ & $30-40 \%$ \\
\hline $\begin{array}{l}\text { Parcialmente regular } \\
\qquad 3 \mathrm{CTs}\end{array}$ & $\leq 72$ meses & 50 pessoas & $4-6$ & $\begin{array}{c}\text { Psicólogos; Assistentes Sociais; téc/ } \\
\text { aux enfermagem }\end{array}$ & $50-60 \%$ \\
\hline $\begin{array}{l}\text { Irregular } \\
12 \mathrm{CTs}\end{array}$ & $\geq 40$ meses & $\begin{array}{l}\text { Entre } 60-80 \text { pessoas; } \\
\text { apenas. } 01 \text { CT recebe + } \\
\text { de } 100 \text { pessoas }\end{array}$ & $0-1$ & Psicólogos & $70-80 \%$ \\
\hline
\end{tabular}

O perfil do grupo regular totalizou três CTs. São características destas comunidades: tempo de existência igual ou superior a 20 anos; a capacidade de atendimento entre 10-35 internos e o quadro técnico entre 10-15 profissionais das áreas da psicologia, assistência social, técnicos e auxiliares de enfermagem, educadores físicos e nutricionistas. Destas instituições, duas remuneram seus profissionais conforme as Consolidações das Leis de Trabalho (CLT) e uma disponibiliza um "valor simbólico" [sic] aos colaboradores. Quanto ao índice de desistência/abandono do tratamento neste perfil, houve variação entre $30-40 \%$.

Já nas três instituições que compõem o grupo parcialmente regular, o tempo de existência e atuação foi inferior a 6 anos; capacidade para 50 internos e a equipe de trabalho possui entre 4-6 profissionais, sendo todos voluntários das áreas de psicologia, assistência social e técnicos/auxiliares de enfermagem. O índice de desistência/abandono variou entre 50-60\%.

No perfil irregular totalizaram 12 comunidades terapêuticas $(66,6 \%)$. Estas possuem menos de três anos de existência e alegam ter capacidade para mais de 60 internos, com exceção de uma comunidade, que recepciona mais de 100 pessoas. Neste último caso, a instituição acolhe não só usuário de substâncias psicoativas, mas também idosos e desabrigados. $O$ índice de desistência do tratamento foi descrito como superior a 70\%. Todavia, não há um controle dessas informações nas CTs dos perfis parcialmente regular e irregular.

De todas as instituições pesquisadas, seis CTs (33\%) relataram que pelo menos um de seus membros técnicos ou responsáveis já realizou cursos de capacitação e atualização na área de transtornos relacionados ao uso de substâncias. Os cursos presenciais foram ofertados pelo Centro Regional de Referência (CRR/ RO) e pela rede Cruz Azul no Brasil (SC). Os cursos a distância foram ofertados pela Secretaria Nacional de Políticas sobre Drogas (SENAD), intitulado "Sistema para detecção do uso abusivo e dependência de substâncias Psicoativas: encaminhamento, intervenção breve, reinserção social e acompanhamento - SUPERA" e o curso "Prevenção do Uso de Drogas em Instituições Religiosas e Movimentos Afins - 'Fé na Prevenção'", também do SENAD. Não houve identificação de outras capacitações, além das supracitadas. As 12 instituições restantes nunca participaram de cursos ou capacitações na área, correspondendo a 67\% da amostra.

No que se refere à clientela atendida, 15 (83,3\%) CTs atendem somente homens e três $(16,6 \%)$ atendem exclusivamente mulheres. Nenhuma CT atende público misto. O nível socioeconômico dos usuários e de suas famílias não é relevante para ingresso em 17 CTs. 
Apenas uma instituição declarou que, se a pessoa possuir condições financeiras de custear um tratamento, ela não pode participar do programa, uma vez que é "para quem não tem condições" (sic).

Em relação à faixa etária da clientela, cinco $(27,7 \%)$ instituições atendem maiores de 18 anos até 70 anos (perfil regular e parcialmente regular); uma instituição $(5,5 \%)$ recebe menores de idade, apenas com encaminhamento judicial e não há limite máximo de idade; sete $(38,8 \%)$ comunidades recebem somente maiores de 18 anos, mas não têm limite de idade máxima; e cinco $(27,7 \%)$ CTs não possuem faixa etária estipulada mínima ou máxima estipuladas (estas inseridas no perfil irregular).

Todas as CTs declararam ofertar tratamento para todos os tipos de substâncias psicoativas, sendo que o programa de tratamento não varia conforme a substância de abuso. Nos últimos 6 meses, 10 (55,6\%) instituições declararam que o crack, o álcool, a cocaína, a maconha e o tabaco foram as principais substâncias consumidas antes do início do tratamento, em ordem decrescente de representatividade. Não ficou claro se os casos de uso problemático de maconha e tabaco eram em associação com outras substâncias ou não. Em todas as instituições, o crack desponta como a principal substância de abuso e principal motivo da internação, seguido do álcool.

No tocante às metodologias empregadas como tratamento, o perfil regular possui equipe técnica composta por psicólogos, assistentes sociais, enfermeiros, nutricionistas, educadores físicos e egressos que completaram o tratamento e desejam trabalhar na comunidade. Estes recebem capacitação técnica, passam a ser chamados "conselheiros" ou monitores e realizam atividades junto aos residentes da CT. Esta CT recebe financiamento público.

O perfil parcialmente regular, empregado em três instituições, preconiza como meta terapêutica a criação de vínculos afetivos, o resgate da convivência, bem como o crescimento pessoal como ideias centrais para a recuperação. A equipe técnica é formada por profissionais da psicologia, assistência social, técnicos de enfermagem e ex-internos. As CTs são mantidas por financiamento público e doações, tanto de empresários (principalmente donos de supermercados) quanto da população geral. O perfil irregular emprega estratégias de cunho religioso como alternativa exclusiva de tratamento, o que corresponde a 77,8\% da amostra; não possuem equipe técnica, nem contato com o CAPS AD, ou demais dispositivos de saúde. As CTs são vinculadas a igrejas evangélicas e se mantêm por meio de doações.

Tendo em vista que as 18 instituições pesquisadas ofertam alguma atividade religiosa optou-se por descrever a frequência e quais atividades são empregadas como "programação religiosa". No perfil regular ocorrem missas e cultos evangélicos, de modo alternado. Nestes, a participação do interno é declarada como opcional e a frequência é de, no máximo, duas vezes por semana.

Em todas as instituições do perfil parcialmente regular e em apenas uma do perfil irregular, as atividades religiosas são de cunho protestante e englobaram: "devocional (leitura e reflexão bíblica todas as manhãs); cultos (um dia na semana e aos finais de semana à noite) e orações (diariamente, antes das refeições e individuais)". A participação também foi descrita como opcional.

Há predomínio de CTs evangélicas no perfil irregular. Em 13 (72\%) instituições, a programação religiosa inclui: devocional (tempo destinado a orações, leitura e reflexões bíblica - todas as manhãs); cultos evangélicos (pela manhã e à noite, praticamente todos os dias); orações diárias (de agradecimento antes das refeições, de "cura e libertação" e em momentos confessionais); vigílias (orações na madrugada, pelo menos uma vez por semana; e leitura/meditação individual da bíblia (diariamente). Nestas CTs a participação nas atividades religiosas é sistematicamente requerida, de modo que, se a pessoa não participar, deverá realizar atividades consideradas punitivas, como por exemplo, lavar o banheiro, recolher o lixo, entre outras.

As atividades descritas como laborterapia são empregadas no intuito de desenvolver habilidades profissionais nos internos, colaborar na manutenção da CT e também entretê-los. Identificou-se que, em todas as instituições pesquisadas, os internos são responsabilizados pela cozinha (limpeza, organização e preparo dos alimentos, lavagem da louça e servir as refeições) e pela limpeza e organização da comunidade terapêutica. Nas CTs do perfil regular, observou-se, além das atividades já descritas, a criação de animais, cultivo de hortas e plantas, práticas de alfabetização e atividades físicas (musculação e natação), além de trabalhos artesanais.

No perfil parcialmente regular, há o emprego de atividades de construção e marcenaria. Ainda neste perfil, sinalizamos a confecção e venda de pães e bolos (especificidade nas CTs femininas), e o cultivo de hortas e criação de animais (galinhas e porcos). Em 10 (55,5\%) 
instituições do perfil irregular há oferta de cultivo de hortaliças e criação de animais, tanto para venda como para consumo interno. Apenas uma CT do perfil irregular utiliza o que autodenominaram como "atividade de reflexão" - momento em que o interno fica sozinho para refletir sobre os "maus comportamentos de quando estava no mundo das drogas e no que fará quando sair da comunidade" (sic) - e não propõem nenhuma outra atividade enquanto laborterapia. As instituições que se limitam à limpeza dos locais e atividades da cozinha totalizaram seis CTs (33,3\%).

Acerca dos critérios de ingresso, nove (50\%) comunidades (todas do perfil irregular) não solicitam exames físicos e mentais para internação, mas realizam triagem cadastral própria. As referidas instituições não possuem critérios de elegibilidade e recebem qualquer tipo de comorbidade: "não podemos negar ajuda a quem precisa, ninguém será lançado fora" (sic) acrescentou um dos respondentes. Outro dado observado foi o receio em conectar-se à rede de Atenção Psicossocial, principalmente ao CAPS AD, onde cinco dirigentes o vincularam à oferta de medicações psicotrópicas e sinalizaram o medo de "substituir uma droga por outra" (sic).

Todas as CTs do perfil regular e parcialmente regular e uma do perfil irregular solicitam exames físicos e mentais para efetivar a internação e recorrem ao CAPS $A D$ para os exames rápidos e intervenções psiquiátricas, quando necessário. Estas não recebem indivíduos portadores de doenças contagiosas, degenerativas e/ou enfermidades crônicas que exijam cuidados intensivos, nem pessoas com problemas judiciais (foragidos). As demais (11 CTs) recebem qualquer comorbidade e não recorrem ao CAPS AD. Destaca-se que estas comunidades são as mesmas que ofertam maior número de vagas e também as que têm os maiores índices de desistência do programa.

Em todas as instituições pesquisadas a alta é administrativa. Deste modo, a evolução da pessoa em recuperação é discutida pela equipe responsável e leva-se em consideração a dedicação nas atividades do programa, além do contato com a família, a autopercepção do interno, conduta, entre outros fatores. Se a equipe entender que o interno não está "pronto" (sic), mesmo este tendo cumprindo o tempo previsto para o programa, ele não receberá alta.

As instituições do perfil regular ofertam encontros coletivos e visitas até um ano após a saída da instituição. As instituições do perfil parcialmente regular mantêm contato por telefone e visitas domiciliares esporádicas, sem prazo determinado. Nas CTs do perfil irregular o contato pós-alta ocorre somente nos cultos.

Destaca-se ainda, dentre os resultados: 1) quanto maior o tempo de existência/atuação da CT, maior o quadro técnico-profissional, menor o índice de desistência do tratamento e menor a oferta de vagas; 2) a oferta de atendimento é maior em CTs que não possuem planejamento terapêutico e orçamentário e não possuem suporte técnico especializado; 3) a presença da categoria Psicologia nos tratamentos ofertados em Rondônia, haja vista que em todos os perfis aqui descritos há a atuação destes profissionais. As atividades por eles desenvolvidas incluem atendimento psicoterápico, individual e em grupo, palestras sobre dependência química, convivência entre os pares e prevenção à recaída.

\section{Discussão}

O levantamento realizado pelo Instituto de Pesquisa Econômica Aplicada - IPEA (2017) mapeou 1.963 CTs em todo o Brasil, dentre as quais 16 CTs foram localizadas em todo o Estado de Rondônia, dados divergentes dos encontrados nesta pesquisa (18 CTs somente na capital). Quanto à participação das CTs de Rondônia em organismos nacionais como a Federação Brasileira de Comunidades Terapêuticas (FEBRACT, 2019), sabe-se que das $37 \mathrm{CTs}$ identificadas no último mapeamento realizado SEPAZ, apenas uma é filiada à FEBRACT, que atualmente conta com 152 CTs cadastradas.

Os dados aqui analisados apontaram um considerável crescimento de CTs, todavia sem engajamento em rede e sem reconhecimento apropriado das práticas de tratamento disponibilizadas. As instituições investigadas neste estudo seguem, em seus traços predominantes: maior oferta de atendimento ao público adulto masculino; o emprego de práticas religiosas e atividades de laborterapia como plano de tratamento; abstinência como meta terapêutica; punição para condutas consideradas inadequadas; equipe composta essencialmente por egressos (ex-internos); escassez de profissionais especializados e de protocolos clínicos de tratamento; alto índice de evasão e desconexão com o CAPS AD e Rede RAPS.

A RAPS foi criada com o intuito de solidificar uma rede horizontal de cuidados às pessoas em sofrimento mental e também às usuárias de substâncias psicoativas (Vasconcelos et al., 2018); em síntese, regulamentava

Estudos de Psicologia, 23(3), julho a setembro de 2018, 325-333 
toda a Rede de Atenção Psicossocial (Ministério da Saúde, 2011). Em 2019 o Ministério da Saúde lançou uma Nota Técnica que passou a regular os dispositivos de saúde mental e as demais portarias tornaram-se acessórias e complementares.

Esta Nota institui que a Rede de Atenção Psicossocial passa a ser formada pelos seguintes serviços: os Centros de Atenção Psicossocial (CAPS), em suas diferentes modalidades; o Serviço Residencial Terapêutico (SRT); Unidades de Acolhimento (adulto e infantil); Enfermarias especializadas em Hospital Geral; Hospital Psiquiátrico; Hospital-Dia; Atenção Básica; Urgência e Emergência; Ambulatório Multiprofissional de Saúde Mental e as Comunidades Terapêuticas.

A referida Nota também preconiza harmonia entre todos os serviços de saúde mental, aliados aos princípios organizativos do SUS - os quais devem subsidiar o atendimento à saúde pública no Brasil. Todavia, destaca-se a dificuldade de articulação observada entre CTs e CAPS AD na prática do cuidado a usuários de álcool e outras drogas. Faria e Schneider (2009) explicitam que os modelos de tratamentos são organizados a partir da racionalidade teórico-metodológica que os fundamentam. O agravante, segundo Schneider (2010, p. 689), é quando a "racionalidade religiosa se aplica como uma doutrina moral", muitas vezes camuflada de modalidade de tratamento à saúde.

O cerne desta discussão é a oferta de tratamentos vinculados à rede de saúde, calcados em preceitos proibicionistas, moralistas e religiosos, que ocorrem sem as condições físicas, técnicas e éticas necessárias, como apontaram os resultados desta pesquisa e é ratificado em diversos estudos nacionais (Bolonheis-Ramos \& Boarini, 2015; Costa, Mota, Paiva, \& Ronzani, 2015; Perrone, 2014; Petuco, 2015; F. M. L Ribeiro \& Minayo, 2015; Vasconcelos et al., 2018).

Apesar da ausência de protocolos clínicos, de fiscalização e monitoramento, as CTs estão ganhando espaço e financiamento enquanto os serviços especializados estão enfraquecendo (Vasconcelos, Paiva, \& Dalla Vecchia, 2018). A carência de serviços públicos para atender a demanda, somada à baixa integralidade, intersetorialidade e escassez de recursos técnicos e operacionais não devem subsidiar a diversificação de serviços desvinculados dos protocolos preconizados pelo Ministério da Saúde com a conhecida justificativa de suprir lacunas (M. Ribeiro et al., 2016).

As diretrizes precisam estar engajadas em fortalecer os dispositivos especializados em vez de servir de incremento para justificar a inclusão de modalidades terapêuticas não testadas e terceirizadas (BolonheisRamos \& Boarini, 2015; Costa et al., 2015; Vasconcelos et al., 2018). A ausência de propostas alinhadas entre as instâncias governamentais nos setores da saúde, segurança pública e assistência social impulsiona práticas antagônicas de cuidado aos usuários de álcool e drogas e legitima o isolamento via internação prolongada (Bolonheis-Ramos \& Boarini 2015) - vívido fantasma manicomial.

$\mathrm{Na}$ tentativa de alinhar o preconizado nas Políticas sobre Drogas e os tratamentos vigentes no país, a Procuradoria Federal dos Direitos do Cidadão (2013) divulgou uma Nota pública com o objetivo de contribuir para a compreensão dos aspectos legais que definem o papel e a atuação das CTs. Em síntese, a nota explicita que não serão considerados estabelecimentos de saúde as CTs que não estiverem de acordo com o preconizado pela Lei $n^{\circ} 10.216 / 2001$; que os recursos que forem repassados pelo poder público às CTs que não se enquadrarem na referida Lei e legislações correlatas não poderão integrar o conjunto de rubricas orçamentárias relativas ao Sistema Público de Saúde; e que a celebração de vínculos entre CTs e o poder público só poderá ocorrer se as CTs estiverem devidamente dentro dos quesitos estabelecidos pela Resolução $n^{\circ} 29$, de 30 de junho de 2011 da Agência Nacional de Vigilância Sanitária (ANVISA).

A resolução supracitada "dispõe sobre os requisitos de segurança sanitária para o funcionamento de instituições que prestem serviços de atenção a pessoas com transtornos decorrentes do uso problemático de drogas, em regime de residência, tendo como principal instrumento terapêutico a convivência entre os internos" (ANVISA, 2011, p. 1); e atua através da Rede RAPS e em parceria com Sistema Único de Saúde (SUS).

A Resolução $N^{\circ} 01$ do Conselho Nacional de Políticas sobre Drogas (CONAD) de agosto de 2015, validou as CTs como unidades de apoio e a articulação destas com a rede de saúde foi recomendada. O que foi ratificado pela Nota Técnica 11/2019 com a inclusão das CTs como serviços de saúde mental, oficialmente vinculadas à rede RAPS. Existe o interesse na definição estrutural dos serviços de atenção/tratamento e nas exigências para mantê-los; porém, novos dispositivos continuam despontando, como uma forma de continuar ofertando velhas práticas de tratamento via modelos morais de segregação (Petuco, 2015). 
As oscilações supracitadas expõem a tendência do Estado brasileiro em adotar medidas políticas centradas em vertentes moralistas e proibicionistas, que transitam ora entre "Guerra às Drogas", ora na repressão à demanda por meio da internação (BolonheisRamos \& Boarini 2015). Reitera-se a importância de tratamentos adequados às necessidades da população-alvo, pautados em abordagens metodológicas específicas, que garantam a defesa da laicidade e ofereçam intervenções embasadas ética, técnica e cientificamente, como ocorre em outros países, no lugar de práticas que recorram majoritariamente ao fundamentalismo moral e/ou religioso.

O Conselho Regional de Psicologia (2016) reafirma a necessidade de que desses tratamentos sejam "qualificados, sistemáticos e baseados em evidências, a exemplo daqueles desenvolvidos para outros problemas de saúde" (p. 3). As atividades desenvolvidas por todas as classes profissionais atuantes em CTs precisam ser analisadas, haja vista o baixo índice de instrução teórica e técnica aqui apresentado. Urge também repensar o processo formativo na área da saúde, especificamente na saúde mental, no intuito de primar por profissionais hábeis no domínio das competências e habilidades requeridas e cidadãos orientados eticamente, conscientes das políticas de humanização e atuantes na defesa dos Direitos Humanos.

Pesquisas que ambicionem identificar protocolos clínicos, analisar a eficácia dos tratamentos ofertados em CTs e a funcionalidade da parceria com a rede SUS e RAPS poderão subsidiar a concretização de uma política de atenção integral de usuários de álcool e outras drogas a partir da lógica da redução de danos, além de fomentar capacitações pontuais para dirigentes de CTs e demais dispositivos da rede.

Por fim, vale ressaltar que é imperativo garantir serviços que contemplem a pluralidade da pessoa em recuperação, com planejamento terapêutico desenvolvido por profissionais especializados, que não firam os direitos constitucionais e que sejam acessíveis, disponíveis, eficientes e humanizados (NT, 11/2019). As problemáticas apresentadas nesta pesquisa não são exclusivas das comunidades terapêuticas, haja vista que no Brasil, os serviços de saúde, de maneira geral, padecem pela falta de metodologias interventivas mais precisas, bem como de critérios e processos de avaliação fidedignos, tanto no que diz respeito à implantação de políticas de saúde, quanto no acompanhamento e avaliação dos resultados obtidos.

\section{Agradecimentos}

Agradecimentos à CAPES (Coordenação de Aperfeiçoamento de Pessoal de Nível Superior) pela concessão de bolsa durante todo o período de realização desta pesquisa.

\section{Referências}

American Psychiatry Association. (2013). Diagnostic and statistical manual of mental disorders - DSM -5. (5 $5^{\mathrm{a}}$ ed.). Washington: Autor

Arnau, D. C. (2006). Comunidades terapéuticas em España: situación actual y propuesta funcional. Madri: Grupo GID.

Bolonheis-Ramos, R. C. M., \& Boarini M. L. (2015). Comunidades terapêuticas: "novas" perspectivas e propostas higienistas. História, Ciência e Saúde, 22(4), 1231-1248. doi: 10.1590/ S0104-59702015000400005

Conselho Regional de Psicologia (2016). Dossiê - relatório de inspeção de comunidades terapêuticas para usuários(as) de drogas no estado de São Paulo: mapeamento das violações de direitos humanos. São Paulo, SP: Autor.

Costa, P. H. A., Mota, D. C. B., Paiva, F. S., \& Ronzani, T. M. (2015). Desatando a trama das redes assistenciais sobre drogas: uma revisão narrativa da literatura. Ciência \& Saúde Coletiva, 20(2), 395-406. doi: 10.1590/1413-81232015202.20682013

Faria, J. G., \& Schneider, D. R. (2009). O perfil dos usuários do CapsadBlumenau e as políticas públicas em saúde mental. Psicologia \& Sociedade, 21(3), 324-333.

Federação Brasileira de Comunidades Terapêuticas. (2019). Filiadas. Recuperado de http://febract.org.br/portal/filiadas/

Instituto de Pesquisa Econômica Aplicada. (2017). Nota Técnica n. 21 (Diest): Perfil das comunidades terapêuticas brasileiras. Recuperado de http://www.ipea.gov.br/portal/index. php?option=com_content\&view=article\&id=29865

Lei no 10.216, de 6 de abril de 2001 (2001, 6 de abril). Dispõe sobre a proteção e os direitos das pessoas portadoras de transtornos mentais e redireciona o modelo assistencial em saúde mental. Recuperado de http://www.planalto.gov.br/ccivil_03/leis/leis_2001//10216.htm

Ministério da Saúde. (2011). Portaria no 3.088, de 23 de dezembro de 2011. Institui a Rede de Atenção Psicossocial para pessoas com sofrimento ou transtorno mental e com necessidades decorrentes do uso de crack, álcool e outras drogas, no âmbito do Sistema Único de Saúde (SUS). Diário Oficial da União.

Ministério da Saúde. (2019). Nota Técnica № 11/2019 CGMAD/ DAPES/SAS/MS. Recuperado de http://pbpd.org.br/wp-content/ uploads/2019/02/0656ad6e.pdf

Morais, P. R. (2007). Estatística para Psicólogos que não gostam de números. Santo André: Editores Associados.

Perrone, P. A. K. (2014). A comunidade terapêutica para recuperação da dependência do álcool e outras drogas no Brasil: mão ou contramão da reforma psiquiátrica? Ciência \& Saúde Coletiva, 19(2), 569-580. doi: 10.1590/1413-81232014192.00382013.

Petuco, D. R. S. (2015). Era uma vez: uma pequena história do cuidado e das políticas públicas dirigidas a pessoas que usam álcool e outras drogas. In M. B. Teixeira \& Z. Fonseca (Orgs.), Saberes e práticas na Atenção Primária à Saúde: cuidado à população em situação 
de rua e usuários de álcool, crack e outras drogas (pp. 179-200). São Paulo: Hucitec.

Procuradoria Federal dos Direitos do Cidadão. (2013). Comissão Permanente da Defesa da Saúde lança enunciados sobre comunidades terapêuticas. Recuperado de http://pfdc.pgr.mpf. $\mathrm{mp}$.br/informativos/edicoes-2013/novembro/comissao-permanentede-defesa-da-saude-lanca-enunciados-sobre-comunidadesterapeuticas

Resolução nº 29, de 30 de junho de 2011 (2011, 30 de junho). Dispõe sobre os requisitos de segurança sanitária para o funcionamento de instituições que prestem serviços de atenção a pessoas com transtornos decorrentes do uso, abuso ou dependência de substâncias psicoativas. Brasília, DF: Ministério da Saúde, Agência Nacional de Vigilância Sanitária.

Resolução nำ/CONAD, de 19 de agosto de 2015 (2015, 19 de agosto). Regulamenta, no âmbito do Sistema Nacional de Políticas Públicas sobre Drogas - Sisnad, as entidades que realizam o acolhimento de pessoas, em caráter voluntário, com problemas associados ao uso nocivo ou dependência de substância psicoativa, caracterizadas como comunidades terapêuticas. Diário Oficial da União, seção 1.

Ribeiro, F. M. L., \& Minayo, M. C. (2015). Religious therapeutic communities in recovering drug users: the case of Manguinhos, state of Rio de Janeiro, Brazil. Interface - Comunicação, Saúde, Educação, 19(54), 515-526. doi: 10.1590/1807-57622014.0571

Ribeiro, J. M., Moreira, M. R., Bastos, F.I., Inglez-Dias, A., \& Fernandes, F. M. B. (2016). Acesso aos serviços de atenção em álcool, crack e outras drogas - o caso do município do rio de Janeiro, Brasil. Ciência \& Saúde Coletiva, 21(1), 71-81. doi: 10.1590/1413-81232015211.13752014

Ribeiro, M. (2010). Organização de serviços de tratamento para a dependência química: parte I - o estrutural - enquadramento terapêutico. In N. B. Figlie, S. Bordin, \& R. Laranjeira (Orgs.), Aconselhamento em dependência química ( $2^{\mathrm{a}}$ ed.). São Paulo: Roca.
Schneider, D. R. (2010). Horizonte de racionalidade acerca da dependência de drogas nos serviços de saúde: implicações para o tratamento. Ciência \& Saúde Coletiva, 15(3), 687-698. doi: 10.1590/ S1413-81232010000300011

Silva, M. A. R. (2013). Comunidade terapêutica: na mão ou na contramão das reformas sanitária e psiquiátrica? (Dissertação de Mestrado). Recuperado de https://repositorio.ufsc.br/bitstream/ handle/123456789/106996/321219.pdf? sequence $=1$

Silva, J. A., \& Garcia, M. L. T. (2004). Comunidades terapêuticas religiosas de tratamento de dependência química no Estado do Espírito Santo. Jornal Brasileiro de Psiquiatria, 54(4), 243-252.

Silva, L. G., \& Calheiros, P. R. V. (2017). Práticas empregadas no tratamento para dependentes de substâncias psicoativas em comunidades terapêuticas brasileiras: uma revisão sistemática da literatura entre 2005-2015. Cadernos Brasileiros de Saúde Mental, 9(23), 2017, ISSN 2595-2420, Florianópolis - Santa Catarina.

Spohr, B., Leitão, C., \& Schneider, D. R. (2006). Caracterização dos serviços de atenção à dependência de álcool e outras drogas na região da Grande Florianópolis. Revista Ciências Humanas. (39), 219-236. doi: 10.5007/\%25x

Vanderplasschen, W., Vandevelde, S., \& Broekaert, E. (2014). Therapeutic communities for treating addictions in Europe: Evidence, currente practices and future challenges. Lisboa: The European Monitoring Centre for Drugs and Drug Addiction. Recuperado de http://www. emcdda.europa.eu/system/files/publications/779/TDXD14015ENN_ final_467020.pdf

Vasconcelos, M. P. N., Paiva, F. S., \& Dalla Vecchia, M. (2018). O cuidado aos usuários de drogas: entre normatização e negação da autonomia. Gerais: Revista Interinstitucional de Psicologia, 11(2), 363-381. Recuperado de http://pepsic.bvsalud.org/scielo. php?script=sci_arttext\&pid=S1983-82202018000200012\&lng=pt \&tIng $=p t$

Leila Gracieli da Silva, Mestre em Saúde e Processos Psicossociais pela Universidade Federal de Rondônia (UNIR/RO), é

Coordenadora do curso de Psicologia da Faculdade de Ciências Biomédicas de Cacoal (FACIMED). E-mail: leila_gracieli@hotmail.com

Luís Fernando Tófoli, Doutor em Psiquiatria pela Faculdade de Medicina da Universidade de São Paulo (FMUSP), é Professordoutor do Departamento de Psicologia Médica e Psiquiatria da

Faculdade de Ciências Médicas da Universidade Estadual de Campinas (DPMP/FCM/UNICAMP). E-mail: Iftofoli@gmail.com

Paulo Renato Vitória Calheiros, Doutor em Psicologia pela Pontifícia Universidade Católica do Rio Grande do Sul (PUC/ RS), é Professor Associado do Departamento de Psicologia da Universidade Federal de Rondônia (UNIR). E-mail: paulocalheiros@unir.br

Recebido em 02.Nov.17 Revisado em 20.Fev.19 Aceito em 22.Mar.19 